\title{
EMERGENCIES IN GENERAL PRACTICE
}

\section{ANTE-PARTUM HAEMORRHAGE}

\author{
BY \\ FRANK STABLER, M.D., F.R.C.S., F.R.C.O.G. \\ Assistant Gynaecologist, Royal Victoria Infirmary, Newcastle-upon-Tyne
}

It is proposed to discuss ante-partum haemorrhage not from the aspect of its types and their subdivisions, nor from that of its operative treatment, but from the aspect of the family doctor called to a patient's house in the later months of pregnancy because there is bleeding from the vagina.

The term "ante-partum haemorrhage" is restricted to bleeding after the twenty-eighth week of pregnancy. Its pathology is no different from bleeding earlier in pregnancy, but its consequences are likely to be more serious to the mother and management may need to take into consideration the life of the foetus. That it may be a serious condition is shown by the fact that it is still the fourth commonest cause of maternal death in England and Wales. The early management of these cases is of critical importance, and I hope to make it evident that what is not done is as important as what is done. The practitioner's first concern when called to his patient will not be whether she has placenta praevia, accidental haemorrhage, cervical polypus, carcinoma of the cervix, or a ruptured vaginal varix, but how much blood has been lost and what is her general condition.

\section{Slight Haemorrhage}

Slight haemorrhage has occurred and there is no disturbance of the woman's general condition.-To attempt to make an exact diagnosis is dangerous and unnecessary. Overshadowing all the management is the fact that the bleeding may be the first warning haemorrhage of placenta praevia. It is possible that vaginal examination will bring on profuse and dangerous bleeding. Even rough abdominal examination might lead to further bleeding. Gentle abdominal examination may show that the presenting part is in the pelvis. In this case, though placenta praevia is not excluded, one can say that a dangerous degree of praevia is not present and that the urgency is not great. If the presenting part is not engaged the diagnosis is not helped. If a high head or any malpresentation is found it is likely that a dangerous degree of placenta praevia is present. An unusual feature is that the primigravida is likely to be safer than the multigravida. Very seldom does the primigravida go on to profuse and alarming haemorrhage after the first show. The multigravida with her slacker, more accommodating uterus may have a drenching loss as the first evidence of the condition. If the foetal heart rate is altered the case is more likely to be one of accidental haemorrhage.

Without further ado every one of these patients should be referred to hospital for admission. There are many maternity units and nursing-homes staffed by general practitioners, and with his patient admitted the doctor may permit himself a further examination. He might examine with a Sims speculum to exclude polypus, carcinoma, and ruptured vaginal varix. Expert assistance is needed for the treatment of each of these. The removal of polypi from the cervix in pregnancy may lead to severe bleeding needing cautery or suture. The mattress suture needed for ruptured varices may bleed severely from the needle punctures. Carcinoma is of course a rare and dangerous problem.

A woman at the thirty-seventh week of her second pregnancy had a slight, palnless loss. Without attempting to make a diagnosis her doctor sent her into hospital. She arrived in perfect condition. After a week in bed in hospital there had been no further bleeding. The baby was lying somewhat obliquely with the head in the left iliac region. It was decided to examine her vaginally in the operating theatre, with everything set ready for caesarean section. A postgraduate class was invited to attend this examination. The apparently normal cervix was inspected and through the fornices a boggy mass could be felt. In order to press home the lesson that these cases should not be examined vaginally except under these special circumstances I passed a finger through the os, expecting a trickle of blood to ensue. When the finger was withdrawn a cascade of blood followed and soon began to form a steadily enlarging pool on the table. A rapid caesarean section ensured that neither mother nor baby came to any harm, but the class, and I, received a smart lesson.

\section{Moderate Haemorrhage}

Haemorrhage sufficient to affect the woman's general condition has occurred.- Here the practitioner's dilemma is not which cases should be sent to hospital (all should) but whether preliminary treatment is necessary before doing so. Let it be said at once that no woman who is still bleeding should be sent on an ambulance journey without some method of stopping the haemorrhage or of making up for what is lost. If pain is present, and especially if there are some evidences of toxaemia, the bleeding is likely to be due to accidental haemorrhage, but this does not affect the management. In all cases an intramuscular injection of $\frac{1}{4}$ gr. $(16 \mathrm{mg}$.) of morphine should be given. The attendant should then consider such factors as the distance from the hospital, whether labour pains have started, the parity of the patient, how much blood has been lost, whether bleeding is still going on, and the aspect of the patient. I write " aspect," for one glance at a woman's face tells more than exact measurements of blood pressure and pulse rate. Indeed the blood pressure may be gravely misleading because of previously present hypertension.

$\mathrm{He}$ will lean towards immediate dispatch to hospital in those patients whose loss has not been excessive, those who have pain, and in primigravidae, but will not send in one who is still bleeding. For the rest there should be no woman in Great Britain beyond the reach of a domiciliary emergency service (the flying squad), or at least of a resuscitation organization. Whilst awaiting the arrival of the squad the patient should be induced to lie still and quiet. A tight binder may be applied. No doctor should ever feel at all guilty of having made a fuss if the squad arrives and finds the patient in quite good condition : he should feel proud. The converse is dreadful. An alarmed doctor makes hurried arrangements to bundle his patient into an ambulance and so out of his responsibility. One still hears of these patients arriving at hospital dead or expiring. In the experience of the Newcastle Obstetric Emergency Service all cases of accidental haemorrhage will need to be transported to hospital, but many of them will need transfusion of blood before the journey is made. Certainly all patients with placenta praevia will need admission. These emergency cases should all be given Group $O$ rhesusnegative blood, for even if their grouping has been tested there are possibilities of error, technical and clerical. Once Group $O$ rhesus-negative blood has been transfused it is best to continue with this even if the correct blood group has been ascertained.

A doctor's wife had been quite well in her fourth pregnancy until at the thirty-second week she awoke at 4 a.m. to find herself wet. Her husband found her to be in a pool of blood. He called his partner, who gave her morphine, sent for the flying 
squad, and did no more. On the arrival of the squad her blood pressure was $60 / 40$, pulse rate 82 , and she had fainted twice. By 5.10 a.m. the second pint of blood was running in rapidly. A tight binder was applied and by 6 a.m. she was in hospital with a blood pressure of $100 / 70$ and a pulse rate of 100 . There was a stage IV placenta praevia. At 9 a.m. a caesarean section was done. In all 5 pints (2.8 litres) of blood was transfused. She left hospital with a haemoglobin of $82 \%$ and a baby thriving on the breast.

\section{Alarming Haemorrhage or Severe Shock}

The haemorrhage is alarmingly severe or the patient shows severe shock or pain.-There may again be placenta praevia, or there may be concealed accidental haemorrhage or, rarely, a true couvelaire uterus ("apoplexie uteroplacentaire"). According to the degree of unexpelled blood so will be the degree of shock, until in the worst cases one finds a woman with ashen lips, dilated pupils, collapsed or anxiously restless, with hard tender uterus and in severe pain. All of these patients should be given an intramuscular injection of $\frac{1}{4} \mathrm{gr}$. (16 mg.) of morphine as a first step. None of them should be packed into an ambulance forthwith. Raising the foot of the bed is an ineffective procedure. To have any effect on the circulation the feet need to be 18 in. $(45 \mathrm{~cm}$.) above the head, and if this is done any benefit is counteracted by the repeated disturbance necessary to prevent the patient sliding into the bed-head. Overheating should be avoided. The cold skin is an evidence that the body is withdrawing blood to more vital parts. Heat will cause skin vasodilatation and lower the blood pressure further. Blood transfusion is imperative and should precede the ambulance journey or be given during it. If she is left quiet very seldom will a woman fail to improve. The initial catastrophe is usually followed by a rebound. It takes time for the body to muster its resources of hypotension and vasoconstriction, and once these are in action a temporary improvement sets in. By then the squad should have arrived. Manipulations and intervention can only add to the seriousness of the condition unless and until an improvement has been achieved by natural or surgical means.

What should be done if the patient is remote from help and transfusion is not available for at least an hour? To stand idle for longer than this may seem to imperil the patient's life. Many doctors keep a flask of dextran solution and a giving set ready for these emergencies. They should certainly be employed. The solution keeps indefinitely and will maintain blood volume effectively until such time as blood is available. The membranes may be ruptured artificially under certain circumstances: when one is sure that a placenta praevia of severe degree is not present (for example, when the presenting part is well engaged in the pelvis), when recurring labour pains are present, when the woman is a multipara, and especially if labour is premature. The first condition is the most difficult to fulfil, but it is the most important, for to attempt to rupture membranes when the placenta covers the os is dangerous.

\section{Vaginal Plugging and Bimanual Compression}

What is the attendant to do with a patient steadily bleeding and deteriorating and help is to be long in coming ? Is there no means of staunching the flow as a first-aid, temporary measure? The old-fashioned vaginal plug is an effective means of stopping any ante-partum bleeding, but it was abandoned because it was almost never applied efficiently in domiciliary practice. To apply it certainly needs a general anaesthetic. Up to half a pound $(0.22 \mathrm{~kg}$.) of cotton-wool will be needed, and this, soaked in saline, will half fill a bucket. Each pledget when wrung out is packed into the vagina until it is distended to the pelvic walls. The final result will be a hard bolus the size of a foetal head completely filling the pelvic cavity. A tight binder and firm perineal band are then applied. Anything short of this would be useless. One or two sanitary towels placed in the vagina would be more likely to increase bleeding than to stop it. Vaginal plugging is a serious undertaking ; never- theless it is effective as a first-aid measure to stop the bleeding. It could be employed in special circumstances such as in a ship at sea or in a remote area.

A more readily applicable though short-term first-aid measure that can be used during the hour awaiting the arrival of help is bimanual compression. This has always been taught as a means of controlling post-partum haemorrhage, but many are unaware that ante-partum haemorrhage can be stopped by this means. In the desperate case that would decide the attendant to adopt this procedure an anaesthetic is not given. The operator lubricates his right hand (soap will do), forms it into a cone, and by pronating and supinating inserts the whole hand into the vagina. The vaginal vault will be found readily capacious and there a fist is made. The left hand presses on the fundus uteri and so the uterus is squeezed between the two hands.

Twenty-five years ago, when I was district obstetric officer to the Princess Mary Maternity Hospital, it was my duty to call daily on a woman 36 weeks pregnant who had been allowed home from the hospital after one or two small ante-partum haemorrhages because she lived near the hospital and beds were needed. One morning just as I walked in she began a dangerously profuse loss. I was alone and had no materials with me. Bimanual compression was applied and the attention of the neighbours attracted by kicking on the floor. It was an hour before help and an ambulance arrived, but during the whole of that time the bleeding, which was from central placenta praevia, was fully controlled and the patient arrived at hospital in good condition.

\section{Subsequent Management}

What is done for the patient after she arrives in hospital is less a matter for this article than for hospital staffs, but as any one of us may be called on to cope with these patients there are one or two principles that should be laid down. There is little room for definitive treatment between simple rupture of the membranes and caesarean section. A great deal of mismanagement has been occasioned by careless reading of Professor Macafee's admirable article on placenta praevia.* It has been asserted that he was against vaginal examination in cases of ante-partum haemorrhage for fear of inducing bleeding in a patient with placenta praevia. The fact is that Professor Macafee wrote, "A vaginal examination should be made in all cases of suspected placenta praevia," but he emphasized that that examination should never be undertaken anywhere but in hospital, and then only if one is prepared for an immediate caesarean section and that the choosing of the time of this examination is a matter for careful thought. There are few obstetricians who would disagree with these dicta. Another misinterpretation is that conservative treatment of placenta praevia can be carried to the extent of allowing patients with this condition to go home until they are nearer term. Such vagueness is perilous. Macafee restricts this licence ${ }^{\circ}$ decidedly to primigravidae who live near and who have been warned not to permit vaginal examination. It is safest never to allow a woman with any degree of placenta praevia to go home. There is strong evidence that many of the severe haemorrhages in placenta praevia have been precipitated by sexual intercourse.

Simple rupture of the membranes may be employed for placenta praevia type I and for most of type II, or for accidental haemorrhage revealed or mixed. On the other hand, lower segment caesarean section is best suited for placenta praevia types III and IV, and for some of type II in which the placenta is situated posteriorly. These are not clear-cut rules and other factors such as the viability of the child, degree of maturity, and parity may alter the decision. A few cases of concealed accidental haemorrhage may need caesarean section or even caesarean hysterectomy. Bringing down a leg in a breech or transverse lie and permitting spontaneous expulsion are still occasionally employed for either variety of ante-partum haemorrhage, notably in patients who are multigravid and in whom the foetus is dead or so premature that its life is valueless.

*J. Obstet. Gynaec. Brit. Emp., 1945, 52, 313. 
Bipolar version, which carries such a high foetal mortality, is now little employed except in multiparae when foetal survival is unlikely, and then usually well before term. In any event it is doubtful whether it achieves anything more than to ensure thorough rupture of the membranes and escape of liquor amnii.

\section{Conclusion}

All cases of ante-partum haemorrhage are cases for hospital. Accurate diagnosis should not be attempted unless the patient is in hospital. In some cases restoration of the patient's general condition is advisable before she is sent in. If in doubt err on the side of safety, and call the obstetric emergency service. In grave and severe cases restorative measures should always be taken before an ambulance journey. If help is delayed there are first-aid measures that will stop the bleeding, but they should be used only in special circumstances.

Next article on Emergencies in General Practice."Acute Food-poisoning," by Dr. C. Hardwick.

\section{PUBLIC HEALTH AND PREVENTIVE MEDICINE}

\section{ROYAL SANITARY INSTITUTE CONGRESS AT BOURNEMOUTH}

About 2,500 delegates assembled at the annual health congress of the Royal Sanitary Institute, which was held at Bournemouth from April 26 to 29 under the presidency of the Duke of Wellington, Lord Lieutenant of Hampshire. The congress met in ten sections, and in addition there were five special conferences for different categories of workers in the public health service. Representatives from more than forty other countries attended, among them three professors from Moscow.

In his address from the chair of the congress the DUkE of WELLINGTON said that although great improvement in hygiene had taken place during the eighty years of the Institute's existence, much still remained to be done. Visitors from Northern Europe were shocked at the open food shops still to be seen in this country. He wondered whether the rising incidence of cancer might be attributed to the enormously increased consumption of sterilized foods and the use in agriculture of chemical fertilizers. He knew that these possibilities were scouted by many eminent authorities, but every medical discovery had found many people who were unwilling to believe in it at first. He also criticized the pollution of rivers by industrial waste. Another outstanding problem concerned feeble-minded old people. A kind of institution between a mental home and an old people's home was wanted; it was one of the most difficult problems of local government.

The problem of the ageing population was also the theme of the presidential address in the Preventive Medicine Section by Dr. Arthur Massey, chief medical officer to the Ministry of Pensions and National Insurance. But he thought they were now beginning to see this problem in better perspective, and the idea that future workers would have increasing difficulty in supporting their aged community was becoming less insistent than in the recent past.

\section{Training for Public Health}

In the Preventive Medicine Section Professor R. H. PARRY (Bristol) called for closer integration of undergraduate medical training with the public health department and the general practitioner, so that the student might learn more about conditions in home, school, and factory. He believed that in time the general practitioner would be able to take over medical responsibilities at the health clinics and work in close association with the public health staff; but there would always remain the need for certain full-time medical officers to be specially trained for other important duties of the health department.

While it was generally agreed that it was better to prevent than to cure, why was it, asked Professor Thomas McKeown (Birmingham), that when the opportunity was presented, as in the N.H.S., to plan a service on a national scale all the resources were devoted to the treatment of established disease ? It was the result of a widespread belief that health depended mainly upon medical services and particularly upon the hospital service. Yet the improvement in health to-day, as compared with the previous century, was due primarily to the fact that people did not become ill rather than to the treatment they received when they were ill. Disease prevention deserved a higher priority than it was given.

\section{Widening Horizons of Preventive Medicine}

In their own special conference the medical officers of health discussed the widening horizons of preventive medicine. Dr. A. L. Cochrane, after describing the work of the pneumoconiosis unit of the Medical Research Council, operating mainly in a Welsh mining area, said that the diseases which were likely to be important in the future were the chronic disabling diseases with a low case-mortality rate, of which rheumatoid arthritis was an example. The long-term programme of preventive medicine was to investigate the causes of these diseases in order to learn what could be done to prevent them. The first step was to measure the disease prevalence, and for this purpose he described how a representative sample of the community might be taken for survey. Then, with the help of different specialists for each disease, the prevalence in a complete population of bronchitis, diabetes, pulmonary disability, and so on could be estimated. Most techniques for this purpose were now sufficiently far advanced to enable medical officers of health to make a start in measuring the prevalence of some of these diseases in their own area.

Dr. J. H. F. BRoTHERSTON (London School of Hygiene and Tropical Medicine) said that the care of the elderly sick was in many ways the most challenging problem facing the health service to-day. The question must be considered in triple terms : (1) in clinical terms, because efficient diagnosis and treatment shortened the problem of care, reduced disability, and lessened the strain imposed on the social situation; (2) in terms of prevention, for every success in this direction prolonged the period of the old person's independence ; and (3) in terms of the social background. In any foreseeable future there must remain limitations on the availability of hospital beds for old people, and methods must be found of increasing the contribution of the outpatient department by making it an institution which old people could use in comfort. But the general practitioner must always bear the main burden of looking after old people in their homes, and the elderly were becoming an increasing proportion of this responsibility. There was every reason why supporting services should be brought to his aid in the patient's home. Why should the services of physiotherapy, dietetics, social work, and the like be available only if the patient happened to go to hospital ? "It is the extent to which the public health services are able to underpin the home situation which will determine the strength of that situation as a place where more extensive clinical care of old people can be carried out."

\section{Noise at Work}

One symposium at the Congress was devoted to the subject of noise at work, its effect on auditory acuity and on behaviour. Air Vice-Marshal E. D. D. Dickson, consultant in otorhinolaryngology to the R.A.F., said that there was no doubt that, in occupations associated with continual exposure to loud noise, hearing impairment would result. In its early stages this impairment was in the little-used higher-pitch range and did not obviously manifest itself as a disability. An ear which had been exposed to intense noise was seriously injured in the organ of Corti. The 